\title{
Disruption of AMPA Receptor Endocytosis Impairs the Extinction, but not Acquisition of Learned Fear
}

\author{
Gemma L Dalton ${ }^{1,2}$, Yu Tian Wang ${ }^{3,4}$, Stan B Floresco*, , 4 and Anthony G Phillips*,2,4 \\ 'Department of Psychology, University of British Columbia, Vancouver, BC, Canada; ${ }^{2}$ Department of Psychiatry, University of British Columbia, \\ Vancouver, BC, Canada; ${ }^{3}$ Department of Medicine, University of British Columbia, Vancouver, BC, Canada; ${ }^{4}$ Brain Research Centre, Vancouver \\ Coastal Health Research Institute and University of British Columbia, Vancouver, BC, Canada
}

\begin{abstract}
Synaptic plasticity in the form of long-term potentiation (LTP) plays a critical role in the formation of a Pavlovian fear association. However, the role that synaptic plasticity plays in the suppression of a learned fear response remains to be clarified. Here, we assessed the role that long-term depression (LTD) plays in the acquisition, expression, and extinction of a conditioned fear response. We report that blockade of LTD with a GluR2-derived peptide (Tat-GluR2 3 ; $1.5 \mu \mathrm{mol} / \mathrm{kg}$, i.v.) that blocks regulated $\alpha$-amino-3-hydroxy5-methyl-isoxazole-4-propionic acid (AMPA) receptor endocytosis during an initial extinction training session disrupted both the expression and recall of extinction learning. A similar impairment of extinction during training, but not recall, was observed when NMDA receptor-dependent LTD was inhibited through the selective blockade of NMDA NR2B receptors with Ro 25-698I. In contrast, blockade of LTD with Tat-GluR2 3 Y during fear conditioning or during a fear recall test did not effect the expression or recall of either contextual or cue-induced conditioned fear. Similarly, administration of Tat-GluR2 $3 Y$ prior to an extinction recall test did not affect spontaneous recovery or rate of re-extinction in previously extinguished rats. These data demonstrate that AMPA receptor endocytosis does not mediate acquisition or expression of conditioned fear, but may play a role in the extinction of fear memories. Furthermore, these findings suggest that LTD may be a molecular mechanism that facilitates the selective modification of a learned association while leaving intact the ability to form a new memory.

Neuropsychopharmacology (2008) 33, 24I6-2426; doi:I0.1038/sj.npp. I 301642; published online 28 November 2007
\end{abstract}

Keywords: long-term depression; amygdala; NMDA; Pavlovian conditioning; rat

\section{INTRODUCTION}

Pavlovian fear conditioning paradigms have proven to be a valuable tool in elucidating the molecular mechanisms underlying associative emotional learning. In these studies, a previously neutral conditioned stimulus (CS) such as a tone is paired with an aversive unconditioned stimulus (US) such as a footshock. The association formed between the CS and US can elicit a conditioned fear response (CR) when the CS is presented alone. In rodents the most readily observable CRs include freezing, response suppression (Quirk et al, 1995; Killcross et al, 1997; Fendt and Fanselow, 1999; Gewirtz and Davis, 2000; LeDoux, 2000), and autonomic changes such as tachycardia (Young and Leaton, 1994; Nijsen et al, 1998) and increased body temperature

\footnotetext{
*Correspondence: Dr SB Floresco, Department of Psychology, University of British Columbia, 2136 West Mall, Vancouver, BC, Canada V6T IZ4, Tel: + | 604827 53।3, Fax: + I 604822 6923,

E-mail: floresco@psych.ubc.ca or

Dr AG Phillips, Department of Psychiatry, University of British Columbia, 2255 Wesbrook Mall, Vancouver, BC, Canada V6T 2AI, Tel: + I 604822 4624, Fax: + I 604822 7756,

E-mail: aphillips@psych.ubc

Received 23 July 2007; accepted 27 October 2007
}

(Noble and Delini-Stula, 1976). Although the neural and molecular mechanisms underlying the formation of CS-US associations are well established (for reviews, see Davis, 2000; Rodrigues et al, 2004), those mechanisms that mediate the suppression of an established fear response in extinction are less clear.

It is now generally accepted that the suppression of a fear response following extinction occurs as the result of new learning (CS-no US) rather than an erasure of the original CS-US association. This conclusion is based on observations that fear responses can reemerge after unsignaled exposure to the US (reinstatement), following a change in context (renewal), with the passage of time (spontaneous recovery) and that reconditioning occurs faster than initial conditioning (Pavlov, 1927; Rescorla and Heth, 1975; Bouton and Bolles, 1979; Bouton et al, 2006; Robbins, 1990; Westbrook et al, 2002). Further support for this assertion comes from both electrophysiological and psychopharmacological studies of behavioral and synaptic plasticity. For example, long-term potentiation (LTP) is considered to be a candidate mechanism of neural plasticity that mediates the acquisition and storage of new fear memories, particularly in the lateral nuclei of the amygdala. Treatments that block LTP, such as NMDA receptor 
antagonists, calcium channel blockers, and protein synthesis inhibitors, disrupt the extinction of conditioned fear (Falls et al, 1992; Vianna et al, 2001; Santini et al, 2004; Sotres-Bayon et al, 2007). Conversely, drugs that promote LTP can facilitate extinction (Walker and Davis, 2002; Yang and $\mathrm{Lu}, 2005)$. In addition, extinction training is associated with LTP-like changes in firing of neurons in the medial prefrontal cortex recorded from awake, behaving animals (Herry and Garcia, 2002).

Further insight into the cellular mechanisms underlying suppression of a learned fear response comes from studies investigating the role of NMDA receptors in this form of learning. Administration of the nonselective NMDA receptor antagonist, CPP before extinction training has no effect on the acquisition of extinction but does block consolidation of extinction training as evidenced by poor recall on a test conducted $24 \mathrm{~h}$ later (Santini et al, 2001). More recent studies suggest a specific role for the NR2B subunit containing NMDA receptors in the expression and recall of extinction. Sotres-Bayon et al (2007) report that the selective NMDA NR2B subunit-selective antagonist ifenprodil prevents both the expression of extinction and the recall of extinction training $24 \mathrm{~h}$ later. Given that these manipulations also disrupt LTP (Bauer et al, 2002), it has been proposed that impairments in fear extinction induced by NMDA receptor blockade are attributable to disruptions in LTP-like mechanisms that mediate the formation of new learning associated with extinction. However, it is notable that ifenprodil also impairs the acquisition of the original fear association (Rodrigues et al, 2001), suggesting that this compound blocks the acquisition of extinction through a general disruption of learning mechanisms rather than through the specific blockade of behavioral flexibility. As such, it is possible that despite the ability of NMDA receptor manipulations to disrupt both LTP and the acquisition of extinction there may be separate cellular mechanisms that selectively enable the manipulation of an established memory while leaving new memory formation systems intact.

There is increasing evidence to suggest that the formation of a competing memory may not be the only mechanism through which learned fear is suppressed. Quirk et al (1995) reported that the acquisition of learned fear was associated with LTP-like increases in firing in neurons in the lateral amygdala. However, when these animals were subjected to extinction training in the same session, these neurons exhibited a gradual decrease in firing in response to CS presentations. Likewise, Rogan et al (2005) demonstrated that presentations of a safety-associated CS induces a longterm depression (LTD) in firing of lateral amygdala neurons evoked by an aversive CS. Along similar lines, low frequency stimulation-induced LTD in the amygdala is associated with reduced expression of a fear-potentiated startle (Lin et al, 2003). When viewed collectively, these findings suggest that learning-induced LTP may be refined or perhaps reversed during extinction training through neural processes related to LTD (or depotentiation) of synaptic strengths.

The induction of LTD and NMDA-induced $\alpha$-amino3-hydroxy-5-methylisoxazole-4-propionic acid (AMPA) receptor endocytosis can be inhibited by drugs that block NMDA receptors containing the NR2B subunit (Kim et al, 2001; Liu et al, 2004; Yang et al, 2005; Fox et al, 2006; Izumi et al, 2006; Tigaret et al, 2006; Duffy et al, 2007; Wong et al, 2007; but see Hendricson et al, 2002; Morishita et al, 2007). Given that NMDA NR2B antagonists also disrupt extinction of learned fear, the possibility remains that the effects of these manipulations may be attributable to disruption in LTD-like processes, in addition to their effects on LTP. However, LTD can be induced through a number of cellular processes that can be NMDA dependent or NMDA independent (Abramets, 2000; Anwyl, 2006), with a common final step in this cascade entailing the endocytosis of AMPA receptors (Luscher et al, 1999; Luthi et al, 1999; Man et al, 2000). Manipulations that block these processes also disrupt the formation of LTD (Ahmadian et al, 2004). In this regard, it is interesting to note that AMPA receptors show an increased surface expression following fear conditioning (Rumpel et al, 2005; Yeh et al, 2006). Therefore, it is reasonable to propose that a reduction in the expression of learned fear during extinction may be mediated in part by a decrease in the surface expression of AMPA receptors. It follows that disruption of AMPA receptor endocytosis (which selectively blocks the formation of LTD) may exert a selective effect on the extinction of a previously established fear memory, without affecting the acquisition of learned fear itself (formation of a new memory). To test this hypothesis directly, we employed the use of the Tat-GluR $2_{3 \mathrm{Y}}$ peptide, which we have shown previously to block the GluR2dependent, regulated AMPA receptor endocytosis associated with the formation of LTD in structures such as the nucleus accumbens and dorsal hippocampus (Brebner et al, 2005; Fox et al, 2007; Wong et al, 2007).

\section{MATERIALS AND METHODS}

\section{Subjects}

A total of 126 male Sprague-Dawley rats (280-350 g) were used. Rats were housed individually and maintained on a $12 \mathrm{~h}$ light/dark cycle with free access to laboratory chow and water. Rats were given 7-8 days to acclimatize to the colony before undergoing surgery. Behavioral procedures began 79 days after surgeries. All experiments were conducted in accordance with the standards of the Canadian Council on Animal Care and were approved by the Committee on Animal Care, University of British Columbia.

\section{Surgeries}

Rats were anesthetized with $100 \mathrm{mg} / \mathrm{kg}$ ketamine hydrochloride and $7 \mathrm{mg} / \mathrm{kg}$ xylazine and implanted with chronically indwelling jugular catheters. All rats were implanted with a single catheter in the right jugular aimed at the vena cava. The catheter was tied to the vein and the free end of the cannula was passed subcutaneous and anchored dorsally between the scapulae. For the first 5 days postsurgery, catheters were flushed once a day with $0.2 \mathrm{ml}$ of antibiotic solution $(50 \mathrm{mg}$ ampicillin sodium $/ 1 \mathrm{ml}$ saline) and then daily with heparinized saline (10 IU) to maintain catheter patency.

\section{Apparatus}

All training and testing occurred in four identical observation chambers $(30.5 \times 24 \times 21 \mathrm{~cm}$; Med-Associates, 
St Albans, VT, USA) enclosed in sound-attenuating boxes. The chambers were constructed of aluminum (two side walls) and Plexiglas (rear wall, ceiling, and hinged front door). Each chamber was illuminated by a single 100-mA houselight located in the top center of one wall. Auditory stimuli were delivered via a speaker connected to a programmable audio generator (ANL-926, Med-Associates) located in the top-left corner of the same wall as the houselights. Two identical $100-\mathrm{mA}$ stimulus lights, $2.5 \mathrm{~cm}$ in diameter and $7 \mathrm{~cm}$ above the floor, were located on the wall opposite the houselight and speaker. The floor of each chamber consisted of 19 stainless steel rods spaced $1.5 \mathrm{~cm}$ apart. The rods were wired to a shock source and solid-state grid scrambler for the delivery of footshock USs. A video camera connected to a VHS video recorder was mounted above each of the chambers to permit video scoring of the animals' behavior.

Each conditioning chamber was situated on a load-cell platform that recorded chamber displacement in response to each rat's motor activity (Med-Associates). To ensure interchamber reliability, each load-cell amplifier was calibrated to a fixed chamber displacement. The output of the load cell of each chamber was set to a gain (vernier knob, 8) that was optimized for detecting freezing behavior. Load-cell amplifier output from each chamber was digitized and acquired online using Threshold Activity software (Med-Associates). During both the conditioning and extinction sessions, each rat's activity was monitored continuously using the data acquisition system described above. For each chamber, load-cell activity was digitized at $5 \mathrm{~Hz}$, yielding one observation per rat every $200 \mathrm{~ms}$ (300 observations per minute). In all experiments, freezing was quantified by computing the number of observations for each rat that had a value less than the freezing threshold. The freezing threshold was determined in a separate group of pilot animals by comparing load-cell output with an observer's ratings of freezing behavior. To achieve a sensitive freezing threshold, the load-cell gain for all chambers was set to yield a freezing threshold that correlated with the observer's ratings of freezing behavior. Thus, movements such as grooming, head turning, and sniffing that would not be scored by an observer as freezing produced load-cell output that exceeded the freezing threshold. Importantly, the freezing threshold was absolute and was used for each rat and experiment in the present study. To avoid counting momentary inactivity as freezing, an observation was only scored as freezing if it fell within a contiguous group of at least five observations that were all less than the freezing threshold. Thus, freezing was only scored if the rat was immobile for at least $1 \mathrm{~s}$ (Maren, 1998). We verified the threshold output of freezing behavior with video scoring of the animals' response which was defined as the cessation of all movement with the exception of respiration-related movement and nonawake or rest body posture (Sotres-Bayon et al, 2007).

As we were interested in examining a potentially differential effect of Tat-GluR2 $2_{3 Y}$ on contextual and cueinduced fear, Experiment 1 assessed fear reactions in both the conditioning contexts (Context A; for context-associated fear) and a novel environment (Context B; for cueassociated fear). Context A consisted of a standard operant chamber with houselights illuminated, aluminum and
Plexiglas walls and a 'wild berry' car air freshener functioning as an odor cue. Air fresheners were hung from the ceiling of the sound-attenuating box outside the operant chamber. Context B was a standard operant chamber that was illuminated by the two stimulus lights, had striped inserts covering the Plexiglas walls, and a 'new car' air freshener functioning as an odor cue. The allocation of Context $\mathrm{A}$ as the conditioning context and Context $\mathrm{B}$ as the novel context was counterbalanced across animals to control for possible confounding effects of odor/insert on fear conditioning or expression.

\section{Drugs}

Tat-GluR2 ${ }_{3 Y}$ and the scrambled control peptide, TatGluR2 $2_{35}$, were dissolved in $0.9 \% \mathrm{NaCl}$ and administered i.v. at a dose of $1.5 \mu \mathrm{mol} / \mathrm{kg} 60 \mathrm{~min}$ before testing. ( \pm )$\left(R^{\star}, S^{\star}\right)$ - $\alpha$-(4-hydroxyphenyl)- $\beta$-methyl-4-(phenylmethyl)-1piperidine propanol (Ro 25-6981) was dissolved in one part DMSO, two parts $0.9 \% \mathrm{NaCl}$, and administered i.p. at a dose of $6 \mathrm{mg} / \mathrm{kg} 30 \mathrm{~min}$ before testing. Dose and route of administration for Tat-GluR2 $2_{3 y}$ and Tat-GluR2 ${ }_{3 S}$ were chosen with reference to Brebner et al (2005). Dose and route of administration of Ro 25-6981 was chosen with reference to Fox et al (2006). Previous studies from our laboratory (Brebner et al, 2005) have shown that the same dose $(1.5 \mu \mathrm{mol} / \mathrm{kg})$ of fluorescently tagged Tat-GluR2 $2_{3 Y}$ reaches peak concentrations in the brain $90 \mathrm{~min}$ after an i.v. infusion with a single exponential decay with a half-life of $4 \mathrm{~h}$. Accordingly, concentrations of the Tat-GluR2 $2_{3 Y}$ peptide would reach undetectable levels in the brain by $24 \mathrm{~h}$ postinjection. Indeed, in that same study, the behavioral effects of Tat-GluR $2_{3 Y}$ were no longer evident $24 \mathrm{~h}$ after i.v. infusion.

\section{Fear Conditioning and Testing}

Experiment 1: effects of AMPA receptor endocytosis blockade on the acquisition and expression of contextual and cue-induced fear. Experiment 1 was conducted over 3 days. Day 1-Habituation: rats were exposed to the conditioning/testing chambers (Context A and Context B) for $10 \mathrm{~min}$ per chamber. Order of exposure was counterbalanced across animals. Day 2-Conditioning: rats were given five presentations of the tone CS $(4 \mathrm{kHz}, 80 \mathrm{~dB}, 20 \mathrm{~s})$ each coterminating with a $0.8 \mathrm{~mA}$ footshock lasting $0.5 \mathrm{~s}$ (US). The first CS-US pairing was presented $120 \mathrm{~s}$ into the session and the intertrial interval (ITI) between CS-US presentations was $105 \mathrm{~s}$ on average (range 90-120). Conditioning sessions lasted $11 \mathrm{~min}$. Immediately after conditioning, rats were removed from the chamber and returned to their home cage and colony. Day 3-Fear recall tests: rats were placed in each context (A or B) for $10 \mathrm{~min}$, order of exposure was counterbalanced to avoid order effects. For contextual fear tests, rats were given $5 \mathrm{~min}$ to recognize the chamber after which freezing behavior was recorded for $30 \mathrm{~s}$ at $2 \mathrm{~min}$ intervals. For cued fear, rats received five 20-s CS only presentations with an ITI of 2 min. Percent time spent freezing was measured during each tone presentation. Recall test sessions lasted $11 \mathrm{~min}$ per context with animals being held in their home cages between tests while chambers were cleaned (approximately $10 \mathrm{~min}$ ). 
Tat-GluR2 ${ }_{3 Y}$, Tat-GluR2 $2_{3 S}$, or $0.9 \% \mathrm{NaCl}$ (saline) were administered according to a between-subjects design $60 \mathrm{~min}$ before conditioning (day 2) or $60 \mathrm{~min}$ before fear recall test (day 3). When drug treatments were given prior to the fear recall test, assignment to a particular group was matched in a pseudorandom manner to ensure that there were no significant differences between groups in levels of freezing at the end of the fear conditioning session.

Experiment 2: effects of AMPA receptor endocytosis blockade on the acquisition and recall of fear extinction. Experiment 2 was conducted over 4 days, each day in the same context: days 1 and 2 (Habituation and Conditioning) were identical to those described above for Experiment 1. As we were particularly interested in the effects of our manipulation on the progression and recall of extinction training, rats went through an extended extinction training session on day 3 . Thus, during day 3-Extinction training: rats were exposed to 20 presentations of the CS in the absence of the US (mean ITI $180 \mathrm{~s}$, range 120240 s). Day 4-Extinction recall test: 20 presentations of the CS only (mean ITI $180 \mathrm{~s}$, range 120-240 s). Although all rats received $20 \mathrm{CS}$ presentations on 'Extinction recall test' days, data analysis was restricted to the first 10 CS presentations, in accordance with previous studies of this nature (Sotres-Bayon et al, 2007). This was necessary because the majority of rats in all groups extinguished their freezing behavior early in the session and subsequently displayed 'sleeping postures' before all 20 tones were presented. Accordingly, we analyzed data only from time points where all animals were awake (ie for 10 tones).

Before habituation, rats were randomly separated into two experimental squads, one squad would receive drug or control treatments $60 \mathrm{~min}$ prior to Extinction training (day 3 ) and the other squad would receive drug or control treatments $60 \mathrm{~min}$ prior to the Extinction recall test (day 4). On days when animals were not given experimental drug treatments, their i.v. catheters were flushed with heparinized saline as per usual catheter maintenance. Within each experimental squad, rats were matched for levels of freezing near the end of both the fear conditioning and extinction training sessions and assigned to treatment groups in a pseudorandom manner.

Freezing behavior was recorded during each presentation of the tone CS and is expressed as average percent time spent freezing per block of two trials. A preliminary analysis of the data obtained from all rats treated with either saline or the control peptide indicated that there was no effect of the control peptide on any of the behavioral parameters investigated in the present group of experiments (Figure 1). Control peptide-treated rats did not differ statistically from saline-treated counterparts in expression of conditioned fear $(\mathrm{F}(1,30)=0.60$; n.s. $)$, rate of extinction $(\mathrm{F}(9,270)=0.99$; n.s. $)$, or spontaneous recovery of conditioned fear $(\mathrm{F}(1,20)=0.86$; n.s.). As such, data from control peptide and saline-treated rats were combined to form one control group.

Experiment 3: effects of NMDA NR2B receptor subunit antagonism on the acquisition and recall of fear extinction. Experiment 3 was conducted over 4 days, each day in the same context. Days 1, 2, 3, and 4
(Habituation, Conditioning, Extinction training and Extinction recall test) were identical to those described above with the exception of drug treatment details. Ro 25-6981 or vehicle was administered i.p. $30 \mathrm{~min}$ before Extinction training (day 3). Freezing behavior was again recorded during each presentation of the tone CS and is expressed as average percent time spent freezing per block of two trials.

Experiment 4: effects of Tat-GluR2 $2_{3 Y}$ administration on anxiety-like responses as measured using the elevated plus maze. Experiment 4 was conducted to investigate whether the effects of the Tat-GluR $2_{3 \mathrm{Y}}$ peptide may have been induced by an increase in anxiety. The elevated plus maze (EPM) consisted of two opposite facing open arms $(50 \times 10 \mathrm{~cm})$ crossed at a right angle by two enclosed arms $(50 \times 10 \mathrm{~cm})$ with $40 \mathrm{~cm}$ high walls. The apparatus was made of wood, painted black, and was elevated $50 \mathrm{~cm}$ above the ground. At the start of the 10 min testing period, each rat was placed in the central platform of the maze facing an open arm. All sessions were video-recorded and behavior was scored using 'ANYmaze' video scoring software. Time spent in the open arms and in the closed arms was scored across the 10 min testing period. The number of entries into each arm was also recorded. Number of entries and percent time spent in the open arms was taken as an index of anxiety as described previously (Pellow et al, 1985). The apparatus was cleaned with $70 \%$ ethanol between each subject. Tat-GluR2 $2_{3 Y}$ or $0.9 \% \mathrm{NaCl}$ (saline) was administered to separate groups of rats $90 \mathrm{~min}$ before testing. This time point was chosen so that the drug would have been on board an amount of time roughly equivalent to the time points where we saw significant effects on extinction in Experiment 2.

\section{Data Analysis}

For Experiment 1 total percent time spent freezing was calculated for contextual and cue-induced fear and analyzed separately using one-way between-subjects factorial ANOVAs, with drug treatment as the between-subjects factor. For Experiments 2 and 3, percentage freezing to the tone was averaged across blocks of two trials and compared with a two-way between/within-subjects factorial ANOVA, with drug treatment as the between-subjects factor and CS trial as the within-subjects factor. All significant main effects and interactions were further analyzed using Dunnett's comparisons. For Experiment 4 the number of entries and percent time spent in the open and closed arms were analyzed separately using repeated-measures ANOVAs with arm (open, closed) as a within-subjects factor and drug treatment as the between-subjects factor.

\section{RESULTS}

\section{Blockade of AMPA Receptor Endocytosis Does not Effect the Acquisition or Expression of Pavlovian Fear}

There is increasing evidence in support of the notion that LTD involves facilitation of clathrin-dependent endocytosis of postsynaptic AMPA subtype of glutamate receptors, via an AMPA receptor GluR2 subunit-dependent mechanism (Man et al, 2000; Kim et al, 2001). Through a systematic deletion and carboxyl tail truncation, a short stretch of 
amino acids ( ${ }_{869}$ YKEGYNVYG $_{877}$ ) in the carboxyl tail region of the GluR2 subunit has recently been identified as being essential for the expression of hippocampal CA1 LTD (Ahmadian et al, 2004). When delivered into postsynaptic neurons, a synthetic peptide containing this sequence of amino acids (GluR2 $2_{3 Y}$ ) blocks LTD by interfering with the facilitated endocytosis of AMPA receptors, the last step of LTD expression, without affecting any upstream signaling steps (Ahmadian et al, 2004; Brebner et al, 2005). The peptide is fused to the cell membrane transduction domain of the HIV-1 protein (Schwarze et al, 1999) making a TatGluR2 $3 \mathrm{Y}$ peptide, rendering it membrane permeable and capable of exerting its physiological effects following systemic administration (Brebner et al, 2005).

There is a growing body of evidence in support of the hypothesis that administration of the Tat-GluR2 $2_{3 Y}$ peptide in vivo can block the formation of LTD via a disruption of AMPA receptor endocytosis. First, Ahmadian et al (2004) reported that the Tat-GluR2 $2_{3 Y}$ peptide blocks both insulininduced increases in the level of tyrosine phosphorylation of GluR2 and AMPA receptor endocytosis in cultured hippocampal neurons. Second, there have been a number of studies that have implicated AMPA receptor endocytosis as a cellular mechanism that mediates LTD of synaptic strengths. In the same aforementioned study, Ahmadian et al (2004) demonstrated that induction of LTD in hippocampal CA1 slices is associated with increased GluR2 tyrosine phosphorylation, and is prevented by postsynaptic application of the GluR2 $2_{3 Y}$ peptide. Likewise Brebner et al (2005) demonstrate that Tat-GluR2 $2_{3 Y}$ blocks the induction of LTD in nucleus accumbens neurons in an in vitro slice preparation. This is consistent with other studies that have implied a role for AMPA receptor endocytosis in mediating LTD (Wang and Linden, 2000; Xia et al, 2000). Of particular relevance to the present study is the recent report that i.v. administration of the Tat-GluR $2_{3 Y}$ peptide blocks the induction and expression of LTD in the hippocampus in vivo (Fox et al, 2007). Taken together, these studies provide compelling evidence that i.v. administration of the TatGluR2 $_{3 Y}$ peptide may exert its effects on behavior by disrupting cellular processes related to regulated AMPA receptor endocytosis and the induction of LTD.

It has been suggested that LTD might work in conjunction with LTP for the formation of a new memory (Malenka and Bear, 2004). In view of this, we tested whether administration of the Tat-GluR2 $2_{3 Y}$ peptide either before the initial conditioning session or a subsequent fear recall test would affect the expression of a Pavlovian fear association. TatGluR2 $_{3 Y}(n=12)$, saline $(n=13)$, or the scrambled control peptide Tat-GluR2 3 (YGRKKRRQRRR-VYKYGGYNE; $1.5 \mathrm{nmol} / g$; i.v., $n=12$ ) was administered $60 \mathrm{~min}$ before either a conditioning session or a fear recall test session conducted $24 \mathrm{~h}$ after conditioning. Recall of conditioned fear was tested in both the same (for contextual associated fear) and a different (for cue-associated fear) contexts. Blockade of AMPA receptor endocytosis during conditioning did not affect acquisition or consolidation of learned fear. Rats that had been treated with Tat-GluR2 $2_{3 Y}$ before conditioning did not differ from control rats in percent time spent freezing during the last two tones of conditioning (Figure $2 \mathrm{a} ; \mathrm{F}(1,35)=0.66 ;$ n.s.) on day 2 or in total time spent freezing in the conditioning context (Figure 2b;
$\mathrm{F}(2,34)=0.14$; n.s.) or during the tone CS presentations (Figure 2c; $\mathrm{F}(2,34)=0.16$; n.s.) during the fear recall test on day 3. Similarly, blockade of AMPA receptor endocytosis did not affect recall or expression of conditioned fear, as rats treated with Tat-GluR2 $2_{3 Y}$ before the fear recall test did not differ from control rats in percent time freezing in the conditioning context (Figure $2 \mathrm{~b} ; \mathrm{F}(2,34)=0.03$; n.s.) or during the tone CS presentations (Figure $2 \mathrm{~b} ; \mathrm{F}(2,34)=0.35$; n.s.). It is of interest to note that administration of TatGluR2 $2_{3 Y}$ prior to either conditioning or the fear recall test did not effect freezing levels in the nonconditioning context prior to the onset of the first tone (data not shown; $\mathrm{F}(4,56)=0.796 ;$ n.s.). This latter finding suggests that AMPA receptor endocytosis also does not play a role in the generalization of conditioned fear to multiple contexts.

\section{Blockade of AMPA Receptor Endocytosis Disrupts Within-Session Extinction of Conditioned Fear}

Three groups of rats were habituated and conditioned to the test tone as described previously. Tat-GluR2 $2_{3 Y}$, saline or the scrambled control peptide were administered $60 \mathrm{~min}$ before extinction training. There were no significant differences in behavior between the rats treated with saline and scrambled peptide (see 'Materials and methods'). Thus, their data were combined to form one control group for statistical analysis ( $n=11$; Figure 1 ). Recall of extinction training was tested under drug-free conditions $24 \mathrm{~h}$ later. Administration of the Tat-GluR2 $2_{3 y}$ peptide $(n=12)$ significantly disrupted extinction training (tone $\times$ group $(\mathrm{F}(9,189)=2.74, p<0.01)$ with post hoc analyses revealing that peptide-treated rats showed significantly $(p<0.05)$ higher levels of freezing during tones 14-20 than control rats. Figure 3 shows that the percent time of CS presentation spent freezing in control rats reaches $40 \%$ at tone 14 and continues to decline ultimately falling to $20 \%$ by tone 20 . In contrast, rats treated with the Tat-GluR2 3 Y peptide continued to freeze more than $50 \%$ of the time during CS presentations in the latter part of the session. Thus, blockade of AMPA receptor endocytosis, which is associated with LTD, also blocks the initial withinsession extinction of conditioned fear.

Further support for the assertion that blockade of LTD disrupts extinction learning comes from the observation that rats treated with Tat-GluR2 $2_{3 Y}$ peptide before extinction training demonstrate impaired recall of extinction training during a drug-free test conducted $24 \mathrm{~h}$ later (tone $\times$ group $\mathrm{F}(4,84)=3.192, p<0.05)$. This interaction was attributable to the fact that control animals showed a progressive decrease in freezing across the five CS trial blocks $(\mathrm{F}(4,84)=11.44$, $p<0.001)$, a decrease that was not observed in animals treated with the Tat-GluR2 $2_{3 y}$ peptide. Post hoc analyses revealed that while spontaneous recovery of fear was comparable between groups ( $t$-test $p=0.359$ for tone 1$)$, Tat-GluR $2_{3 \mathrm{Y}}$-treated rats showed significantly $(p<0.05)$ higher levels of freezing than control rats during the last two CS presentations.

\section{Blockade of AMPA Receptor Endocytosis During Extinction Recall does not Affect Spontaneous Recovery or Subsequent Rate of Extinction}

In a separate group of rats, administration of Tat-GluR2 $2_{3 Y}$ before recall of conditioned fear did not affect spontaneous 


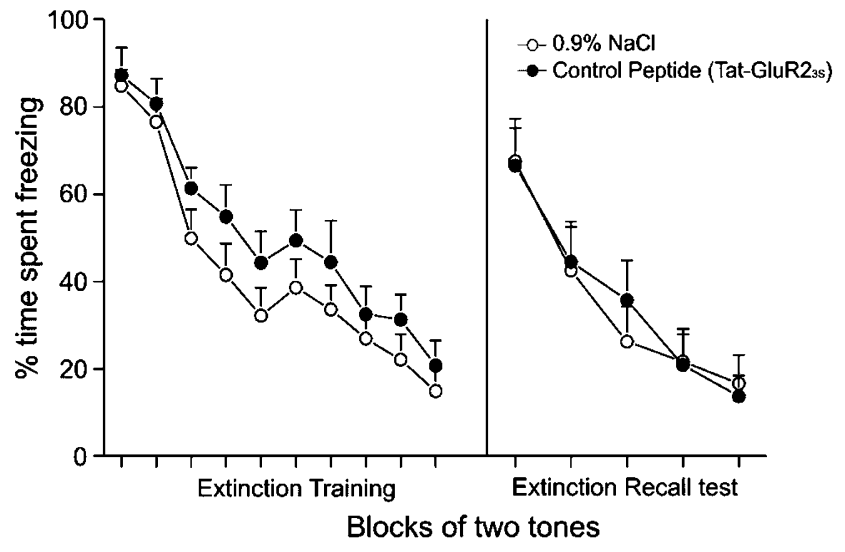

Figure I Rats treated with the control peptide Tat-GluR2 35 ( $1.5 \mu \mathrm{mol} /$ $\mathrm{kg}$, i.v.) 60 min before extinction training do not differ significantly from saline-treated counterparts in the expression or extinction of a learned fear response. Average percentage of freezing to the tone is shown in blocks of two trials for saline (open circles, $n=22$ ) and Tat-GluR2 ${ }_{35}$-treated (closed circles, $n=10$ ) rats. There is also no significant difference between saline $(n=12)$ and Tat-GluR2 $3 s^{-t r e a t e d}(n=10)$ rats during extinction recall. Note: data presented here represent all control data from Experiment 2, including saline data (extinction training) for rats given Tat-GluR2 3 y before the extinction recall test.

recovery or subsequent re-extinction of conditioned fear (Figure 4; Tat-GluR2 $2_{3 \mathrm{Y}}: n=10$; Controls: $n=11$ ). Direct comparisons revealed that rats that had undergone extinction training while drug free and were treated with TatGluR2 $2_{3 Y}$ before an extinction recall test did not differ from controls in percent time spent freezing to the initial tone $(p=0.58)$. Similarly, a two-way ANOVA revealed that there was no significant difference among groups in the percent time spent freezing during each of the 10 tone presentations (five CS trials) within this test day (tone $\times$ group $\mathrm{F}(4,76)=0.34$, n.s.) indicating that rate of extinction was not affected by administration of Tat-GluR2 $2_{3 \mathrm{Y}}$.

\section{Administration of the NMDA NR2B Receptor} Antagonist Ro 25-6981 Before Extinction Training Disrupts Within-Session Extinction of Conditioned Fear

In light of emerging evidence that LTD- and NMDAinduced AMPA receptor endocytosis can also be selectively disrupted by NMDA NR2B receptor subunit-selective antagonists (Kim et al, 2001; Liu et al, 2004; Fox et al, 2006; Tigaret et al, 2006; Duffy et al, 2007; Wong et al, 2007), we used the selective NMDA NR2B receptor subunit antagonist Ro 25-6981 as a positive control for assessing the behavioral effects of LTD blockade. As such, the aim of Experiment 3 was to replicate the effects of the Tat-GluR2 $2_{3 Y}$ peptide on fear extinction using the selective NMDA NR2B antagonist Ro 25-6981. Administration of Ro 25-6981 (6 mg/ kg, i.p., $n=9$, vehicle controls, $n=10$ ) $30 \mathrm{~min}$ before extinction training significantly disrupted extinction training $(\mathrm{F}(9,261)=30.11, p<0.05)$ with post hoc analyses revealing that Ro 25-6981-treated rats showed significantly $(p<0.05)$ higher levels of freezing during tones 12-16 (Figure 5). Interestingly, in contrast to those given TatGluR2 $2_{3 y}$, animals treated with Ro 25-6981 before extinction training showed no deficit in re-extinction during the extinction recall test on day $4(\mathrm{~F}(4,68)=2.29$, n.s. $)$.
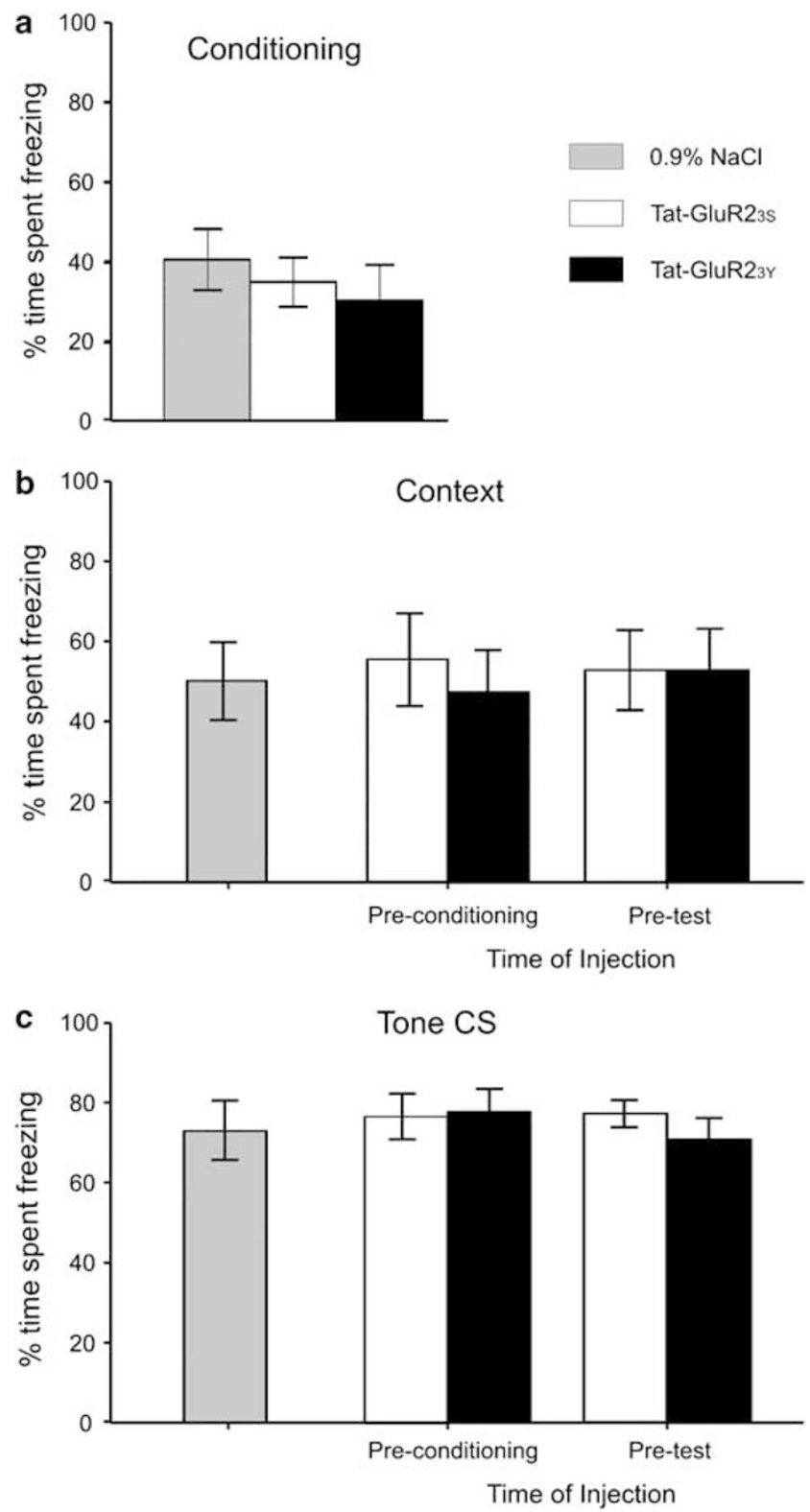

Figure 2 Tat-GluR2 3 y does not affect the acquisition or expression of learned fear (a) during the last two tones of the conditioning session, (b) to the conditioning context, or (c) to a fear-associated tone during recall tests $24 \mathrm{~h}$ later. Mean \pm SEM percentage of time spent freezing during the fear recall test following administration of Tat-GluR2 $3 Y$ (black, $n=12)$ or Tat-GluR2 35 (white, $n=12$ ) before acquisition (middle bars, $b$ and $c$ ) or expression (right bars, b and c) of learned fear. Control animals (gray bars, left) received i.v. injections of saline $(n=13)$ on both days.

\section{Blockade of AMPA Receptor Endocytosis Using Tat-GluR2 $2_{3 Y}$ does not Induce Anxiety-Like Behavior}

It is possible that the disruptive effects of Tat-GluR2 $2_{3 Y}$ administration on extinction training in Experiment 2 are attributable simply to a potential anxiogenic effect of this compound. In consideration of this, we assessed the behavior of saline and Tat-GluR2 ${ }_{3 \mathrm{Y}}$-treated rats on the EPM, an ethologically validated model of anxiety in the rodent (Pellow et al, 1985). Administration of Tat-GluR2 $2_{3 Y}$ $(n=6)$ had no significant effect on number of entries into 


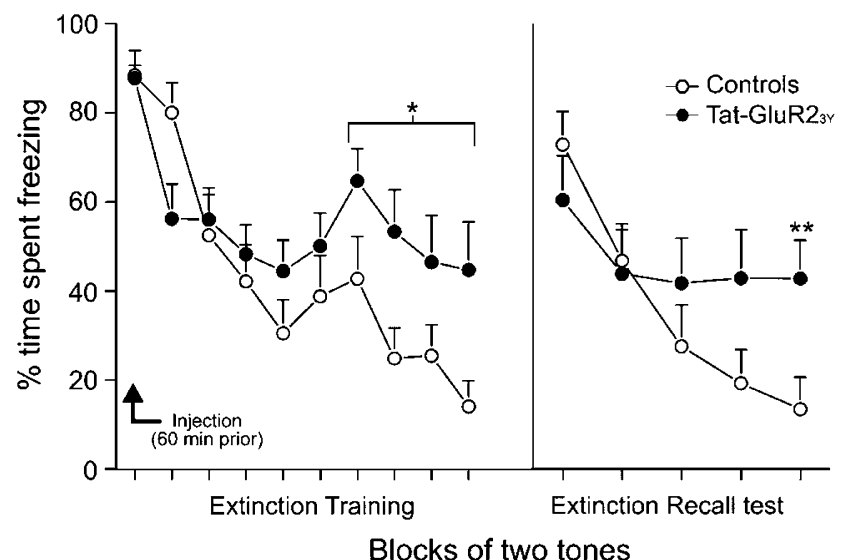

Figure 3 Tat-GluR2 $2_{3 y}$ blocks expression and recall of extinction of learned fear. Average percentage of freezing to the tone is shown in blocks of two trials for Control (open circles, $n=1 \mathrm{I}$ ) and Tat-GluR2 $2_{3}$-treated (closed circles, $n=12$ ) rats. The arrow indicates time of injection. TatGluR2 $_{3 Y}(1.5 \mu \mathrm{mol} / \mathrm{kg}$, i.v., $n=12)$ given $60 \mathrm{~min}$ before extinction training significantly impaired the acquisition of fear extinction (left) as a reflection of this, subsequent rate of extinction during a drug-free recall test $24 \mathrm{~h}$ after extinction training is similarly disrupted (right); $* p<0.05, * * 0<0.0$ l compared to vehicle-treated counterparts.

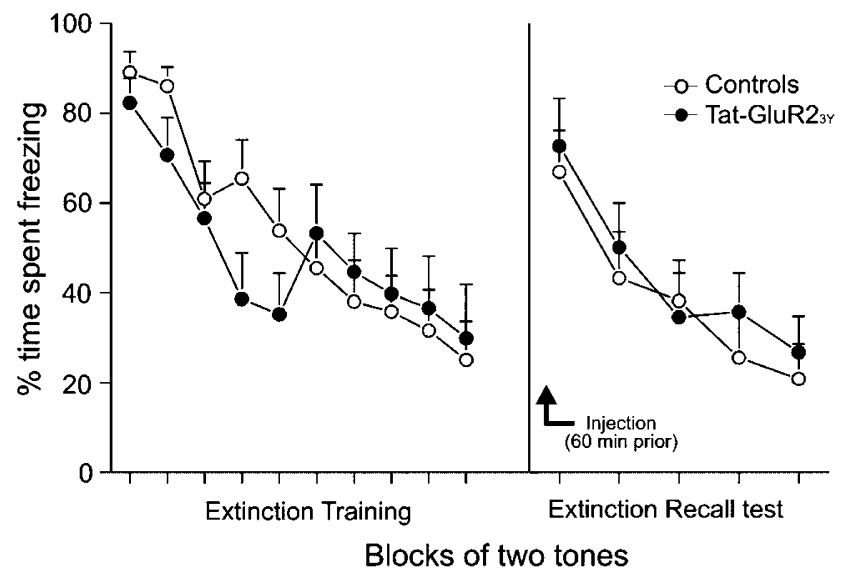

Figure 4 Tat-GluR2 $2_{3 y}$ does not affect expression of a previously acquired extinction memory. Average percentage of freezing to the tone is shown in blocks of two trials for Control (open circles, $n=\mid I$ ) and TatGluR2 $2_{3}$-treated (closed circles, $n=10$ ) rats. The arrow indicates time of injection. Systemic administration of Tat-GluR2 $2_{3 y} 60$ min before extinction recall does not effect spontaneous recovery of fear or recall of extinction training.

the open $v s$ the closed arms (Table $1 ; \mathrm{F}(1,10)=0.41$, n.s.) nor did it effect the percent of time spent in the open $v s$ the closed arms $(\mathrm{F}(1,10)=0.01$; n.s. $)$ relative to saline-treated rats $(n=6)$. The fact that administration of Tat-GluR2 $3 \mathrm{Y}$ does not significantly decrease the number of entries or percent time spent in the open arms compared to the closed arms suggests that the Tat-GluR2 $2_{3 Y}$ peptide does not induce behaviors consistent with increased anxiety. Thus, we may conclude that the failure of Tat-GluR2 $2_{3 Y}$-treated rats to suppress a fear response during the extinction training session of Experiment 2 arises as the result of a specific impairment in extinction learning rather than an anxiogenic property of this compound.

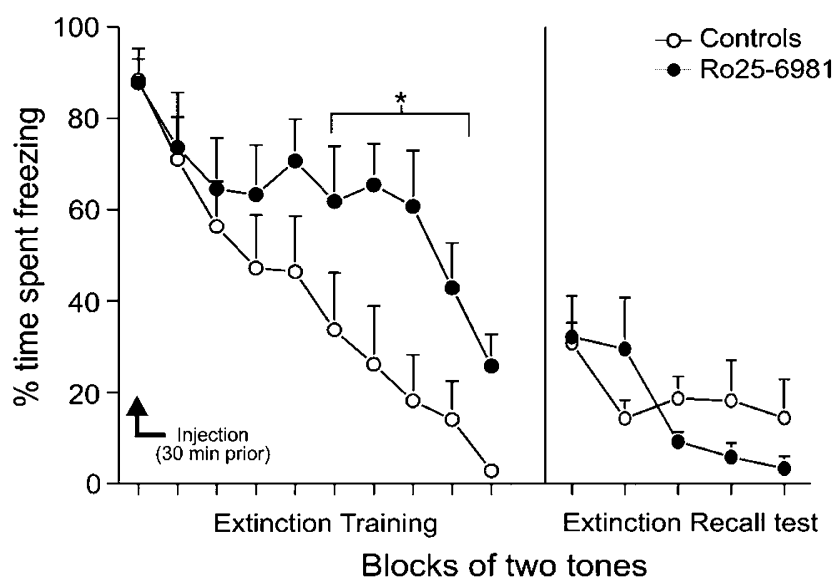

Figure 5 Blockade of NMDA NR2B receptor subunit activation disrupts the acquisition of extinction during extinction training. Average percentage of freezing to the tone is shown in blocks of two trials for Control (open circles, $n=10$ ) and Ro 25-698I-treated (closed circles, $n=9$ ) rats; ${ }^{*} p<0.05,{ }^{*} * p<0.0$ I compared to vehicle-treated counterparts.

Table I Effects of i.v. Injections of Saline and Tat-GluR2 $2_{3 Y}$ on the Number of Arm Entries and in Percentage of Time Spent in the Open or Closed Arms of the Elevated Plus Maze

\begin{tabular}{lcr}
\hline & $\begin{array}{c}\text { Controls } \\
(\mathbf{n}=\mathbf{6})\end{array}$ & $\begin{array}{c}\text { Tat-GluR2 } \\
(\mathbf{n}=\mathbf{6})\end{array}$ \\
\hline Open arm entries & $9.3( \pm 3.1)$ & $6.8( \pm 2.4)$ \\
Closed arm entries & $19.3( \pm 3.4)$ & $15.2( \pm 1.5)$ \\
& $13.5( \pm 2.8)$ & $12.0( \pm 3.6)$ \\
Percent time spent in open arms & $74.8( \pm 4.9)$ & $72.2( \pm 6.7)$ \\
Percent Time spent in closed arms & \\
\hline
\end{tabular}

Data expressed as means ( \pm SEM).

\section{DISCUSSION}

In the present study, we examined the role of GluR2dependent, regulated AMPA receptor endocytosis, which is a cellular mechanism that mediates LTD, in the acquisition, expression, and extinction of a learned fear response. In so doing, we utilized the interference peptide Tat-GluR2 $2_{3 y}$ that disrupts the internalization of AMPA receptors. Here we report that blockade of AMPA receptor endocytosis during initial extinction training significantly disrupted both the expression and subsequent retrieval of extinction learning. A similar effect on expression was observed following selective blockade of NMDA NR2B receptors with Ro 256981. In contrast, administration of Tat-GluR2 $2_{3 Y}$ either prior to fear conditioning or during the recall test did not affect acquisition or expression of contextual or cueinduced fear. Taken together, these data suggested that AMPA receptor endocytosis is involved specifically in the suppression of a learned fear response during extinction training, but is not involved either in the formation of a new associative memory or the retrieval of an established one. LTD of synaptic transmission can be induced through both NMDA-dependent and NMDA-independent processes (for reviews, see Abramets, 2000; Anwyl, 2006). As such, we 
propose that LTD may be one synaptic mechanism that facilitates the selective manipulation of an established memory while leaving intact the ability to form new memory.

It is important to note that expression of behavioral sensitization established previously by repeated treatment with D-amphetamine in a distinct environment was blocked by administration of Tat-GluR2 3 y prior to the test (Brebner et al, 2005), whereas in the present study, similar manipulations did not affect the expression of learned fear or extinction. There are of course many procedural differences between drug-induced behavioral sensitization and recall of extinction of CRs that may explain the effectiveness of Tat-GluR2 $2_{3 Y}$ prior to a test in the former but not the latter situation. Furthermore, these differences raise the possibility of alternative mechanisms of action by which treatment with Tat-GluR2 $2_{3 Y}$ may influence learned associations with drugs of abuse as distinct from salient environmental stimuli, as discussed in the present study.

\section{Manipulations that Disrupt LTD Formation Disrupt Fear Extinction}

The notion that LTD is a form of synaptic plasticity that may facilitate extinction of a learned fear response is supported by previous electrophysiological recordings from amygdala neurons in awake, behaving animals. In a seminal study, Quirk et al (1995) observed that during the initial stages of fear conditioning, neurons in the lateral amygdala display an increase in firing associated with the acquisition of a fear response. However, following repeated extinction trials, CS-evoked activity of these neurons displayed a gradual decrease in activity, resembling a depotentiation of the evoked response. Similarly, Rogan et al (2005) observed that presentation of an aversive CS increased firing of lateral amygdala neurons. However, presentation of a 'safety' CS resulted in a long-lasting depression in firing of amygdala neurons evoked by the aversive CS. In a similar manner, low-frequency stimulation of the lateral amygdala induces a depotentiation of these neurons in vitro and attenuates the expression of fear memory in vivo (Lin et al, 2003). These neurophysiological findings indicate that LTD or depotentiation of synapses in the amygdala may facilitate the extinction of fear memories. Such a mechanism may work in concert with other active learning processes (possibly mediated by the prefrontal cortex) that suppress the expression of a fear response after extinction training (Herry and Garcia, 2002; Burgos-Robles et al, 2007; Corcoran and Quirk, 2007).

Recent psychopharmacological studies provide further support for a role for LTD in the extinction of fear. Sotres-Bayon et al (2007) report impairment in the acquisition of fear extinction in rats treated with the NR2B-subunit-selective NMDA receptor antagonist ifenprodil. Furthermore, this noncompetitive NMDA antagonist disrupts synaptic plasticity in the amygdala (Bauer et al, 2002). Of particular relevance to the present argument is the fact that NMDA NR2B receptor activation is required for the induction of LTD in vitro under some circumstances (Yang et al, 2005; Liu et al, 2004; Woo et al, 2005; Izumi et al, 2006; but see Hendricson et al, 2002; Morishita et al, 2007) and for NMDA-induced AMPA receptor endocytosis in cultured neurons (Kim et al, 2001; Tigaret et al, 2006). Indeed, recent studies have demonstrated that systemic administration of Ro 25-6981 at the same dose used in the present study blocked selectively the induction of LTD while having no effect on LTP in the hippocampus in vivo (Fox et al, 2006; Wong et al, 2007). The Tat-GluR2 $2_{3 Y}$ peptide used in these experiments has also been shown to block the expression of LTD specifically through the blockade of regulated AMPA receptor endocytosis (Ahmadian et al, 2004; Brebner et al, 2005; Fox et al, 2007). Our observations that these two manipulations that disrupt LTD formation (inhibition of AMPA receptor endocytosis or NMDA NR2B receptor antagonism) also disrupt the initial extinction of a fear response during training further support the notion that LTD plays a central role in mediating certain components of fear extinction. The disruption of fear extinction by the Tat-GluR2 $2_{3 Y}$ peptide provides the first direct evidence suggesting that AMPA receptor trafficking is a mechanism through which learned behaviors can be modified in real time, enabling the adjustment of behavior in accordance with the situation at hand. This hypothesis, that LTD plays a critical role in modifying established behaviors, is in keeping with a recent report by Duffy et al (2007). In that study, blockade of NMDA NR2B receptors with Ro 25-6981 disrupted the formation of hippocampal LTD and also disrupted reversal learning in a Morris water maze task, by promoting perseveration, while having no effect on initial spatial learning. These authors concluded that a major function of 'LTD is to augment behavioral flexibility, independent of the specific cognitive requirements of the task,' a notion entirely consistent with the present data.

The use of systemic drug administration in the present study makes it difficult to assess where in the brain these compounds may be acting to disrupt the initial extinction of a fear response. Nevertheless, the studies discussed above strongly suggest that the lateral nuclei of the amygdala may be an important neuroanatomical locus where blockade of AMPA receptor endocytosis or NMDA NR2B receptors would affect this form of learning. However, it is equally plausible that these effects may be due to alterations in synaptic mechanisms in the hippocampus, given that (1) both Tat-GluR2 $2_{3 Y}$ and Ro 25-6981 disrupt LTD formation in the hippocampus (Fox et al, 2006, 2007; Duffy et al, 2007) and (2) inactivation of this region causes a similar impairment in extinction learning (Corcoran et al, 2005). The effects of local administration of these drugs in the hippocampus and amygdala on fear extinction are the topic of current investigation in our laboratory.

Administration of Tat-GluR2 $2_{3 Y}$ before the extinction recall test (conducted $24 \mathrm{~h}$ after extinction training) did not effect the rate of extinction following spontaneous recovery. Under normal circumstances, spontaneous recovery of a learned fear response occurs when an animal is reexposed to the context in which fear acquisition and extinction occurred. Moreover, these extinction curves are usually shifted to the left, and the fear response is extinguished earlier than during the initial extinction training session. As such, it is reasonable to expect that a manipulation that impairs performance during the initial extinction training might also impair rate of extinction following spontaneous recovery. Our observations that rats 
extinguished in a drug-free state, and subsequently treated with Tat-GluR $2_{3 Y}$ before an extinction recall test, did not alter their rate of extinction relative to controls suggest that AMPA receptor endocytosis is involved specifically in the initial manipulation of an established association and is not related to long-term suppression of a previously learned behavior. This pattern of results would also appear to rule out state dependency as an explanation for the present findings. Instead, the removal of AMPA receptors from the synaptic membrane during an extinction training session may be a mechanism through which increases in synaptic strengths that underlie fear memories can be attenuated. This reduction in neuronal excitability may permit new learning about the fear stimulus during extinction that would reduce the impact of conditioned stimuli on behavior. This notion is consistent with previous suggestions that LTD can function to depotentiate synapses that have undergone LTP during the acquisition of the original CS-US association (Massey et al, 2004).

\section{AMPA Receptor Endocytosis does not Mediate the Acquisition or Expression of Conditioned Fear}

In contrast to the effects on extinction, systemic administration of Tat-GluR2 $2_{3 Y}$ had no effect on the acquisition or expression of conditioned fear to an auditory CS or the conditioning context. This lack of effect is not particularly surprising, given (1) the array of evidence that LTP is the primary mechanism underlying the formation of learned fear, and (2) that Tat-GluR2 3 Y does not disrupt LTP formation (Fox et al, 2007). LTP-like changes in neural activity associated with learned fear have been observed in the lateral amygdala (Quirk et al, 1995; Hobin et al, 2003), and treatments that block LTP such as NMDA receptor antagonists, calcium channel blockers, and protein synthesis inhibitors prevent the acquisition of conditioned fear (Maren et al, 1996; Gewirtz and Davis, 1997). It is noteworthy that although blockade of AMPA receptor endocytosis disrupted the suppression of learned fear in the present study, this manipulation did not potentiate the acquisition or expression of a fear response. That is, administration of Tat-GluR2 $2_{3 Y}$ prior to either the acquisition or the expression of conditioned fear failed to increase levels of freezing in the latter stages of conditioning or at the start of the test session. This would suggest that the behavioral effect of AMPA receptor endocytosis blockade is specifically due to its effects on learning and memory systems and does not arise as the result of a general exaggeration of the fear response. In addition, these results also suggest that AMPA receptor endocytosis and the associated LTD do not appear to be involved in the acquisition of learned fear, a conjecture that does not support theories proposing that LTD works in conjunction with LTP to improve a 'signal-to-noise ratio', thereby facilitating learning in an aversive situation (Bienenstock et al, 1982; Martin et al, 2000; Nakao et al, 2002).

The lack of an effect of Tat-GluR2 ${ }_{3 Y}$ on the acquisition of learned fear contrasts with the observation that blockade of NR2B-containing NMDA receptors in the amygdala with ifenprodil disrupts the acquisition of conditioned fear (Rodrigues et al, 2001). In this regard, it is important to highlight that although ifenprodil disrupts LTD formation in the hippocampus (Liu et al, 2004; Massey et al, 2004), it can also disrupt the formation of LTP in the amygdala (Bauer et al, 2002). In contrast, the effect of the more selective Ro 25-6981 on the acquisition of conditioned fear or synaptic plasticity in the amygdala is currently unknown. In addition, AMPA receptor endocytosis occurs downstream of NMDA receptor activation in the induction of LTD (Ahmadian et al, 2004; Mangiavacchi and Wolf, 2004; Moult et al, 2006). Accordingly, activation of NMDA NR2B receptors would be expected to affect a number of different cellular processes, in addition to mediating AMPA receptor endocytosis. As such, the lack of effect of Tat-GluR2 ${ }_{3 Y}$ on the acquisition of conditioned fear may be attributable to a much more selective action of this compound on cellular mechanisms related to synaptic plasticity. It is of interest to note that although the effects of Ro 25-6981 mirrored those of Tat-GluR2 $2_{3 Y}$ on the acquisition of extinction learning during training, rats given Ro 25-6981 before extinction training did not show the same deficit in recall of extinction memory when tested drug free, $24 \mathrm{~h}$ later. This may be attributable to the fact that, unlike those treated with TatGluR2 ${ }_{3 Y}$, Ro 25-6981-treated rats did eventually extinguish (albeit at a slower rate than controls) during the extinction training session. Although this may be a result of variations in drug clearance rates, the differences in the effects of these two compounds on extinction recall do also suggest that NMDA NR2B receptor antagonism may be less effective than Tat-GluR2 $2_{3 Y}$ in disrupting the molecular mechanisms that regulate AMPA receptor endocytosis and/or LTD.

Previous psychopharmacological studies investigating the glutamatergic mechanisms underlying fear conditioning have failed to observe a selective effect on extinction learning that does not affect the initial acquisition of conditioned fear. As noted above, blockade of NMDA NR2B receptors with ifenprodil disrupts not only the acquisition of extinction (Sotres-Bayon et al, 2007), but also the formation of the original Pavlovian association (Rodrigues et al, 2001). In contrast, the present study is distinguished by our observation that inhibition of clathrin-mediated AMPA receptor endocytosis selectively impairs the suppression of an established fear association yet does not effect the formation of a new association. Thus, AMPA receptor endocytosis may serve as a short-term mechanism through which inappropriate responses can be suppressed while leaving other learning mechanisms intact. This would be in keeping with the notion that different stages of memory are mediated through dissociable learning mechanisms that may be mediated by distinct biochemical pathways. Indeed, Myers et al (2006) have recently proposed that mechanisms underlying extinction of recently formed $(<24 \mathrm{~h})$ fear memories may be different from those which mediate extinction of memories that have undergone consolidation. Thus, the early stages of extinction may depend primarily on modification of AMPA receptors via NMDA-independent mechanisms, whereas long-term maintenance of extinction memories is mediated by NMDAdependent forms of plasticity. This supposition is entirely consistent with previous suggestions that both NMDAdependent and NMDA-independent forms of plasticity are required for the full consolidation of a new memory (Kentros et al, 1998; Santini et al, 2001).

To summarize, the present study provides evidence that AMPA receptor endocytosis, which is a cellular mechanism 
underlying the formation of LTD, plays a critical role in facilitating initial extinction of learned fear. We also show that this form of plasticity does not play a role in the original formation or expression of a learned fear response. Thus, regulated AMPA receptor trafficking may be a cellular mechanism that facilitates the initiation of behavioral flexibility in response to changes in associative contingencies, by reducing the strengths of synapses that regulate the expression of established behaviors. Furthermore, by demonstrating that pharmacological manipulations that block the formation LTD can impede the progression of extinction, we provided compelling evidence for a central role of this form of plasticity in mediating adjustments of established associative memories.

\section{ACKNOWLEDGEMENTS}

This work was supported by operating grants from the Canadian Institutes of Health Research and Neuroscience Canada to YTW and AGP, and by a Discovery grant from the Natural Sciences and Engineering Research Council of Canada to SBF. SBF is a CIHR new investigator and a Michael Smith scholar.

\section{REFERENCES}

Abramets II (2000). Neurochemical mechanisms of basic forms of long-term depression of synaptic transmission. Neurophysiology 32: 406-414.

Ahmadian G, Ju W, Liu L, Wyszynski M, Lee SH, Dunah AW et al (2004). Tyrosine phosphorylation of GluR2 is required for insulin-stimulated AMPA receptor endocytosis and LTD. Embo J 23: $1040-1050$.

Anwyl R (2006). Induction and expression mechanisms of postsynaptic NMDA receptor-independent homosynaptic longterm depression. Prog Neurobiol 78: 17-37.

Bauer EP, Schafe GE, LeDoux JE (2002). NMDA receptors and L-type voltage-gated calcium channels contribute to long-term potentiation and different components of fear memory formation in the lateral amygdala. J Neurosci 22: 5239-5249.

Bienenstock EL, Cooper LN, Munro PW (1982). Theory for the development of neuron selectivity: orientation specificity and binocular interaction in visual cortex. J Neurosci 2: 32-48.

Bouton ME, Bolles RC (1979). Role of conditioned contextual stimuli in reinstatement of extinguished fear. J Exp Psychol Anim Behav Process 5: 368-378.

Bouton ME, Westbrook RF, Corcoran KA, Maren S (2006). Contextual and temporal modulation of extinction: behavioral and biological mechanisms. Biol Psychiatry 60: 352-360.

Brebner K, Wong TP, Liu L, Liu Y, Campsall P, Gray S et al (2005). Nucleus accumbens long-term depression and the expression of behavioral sensitization. Science 310: 1340-1343.

Burgos-Robles A, Vidal-Gonzalez I, Santini E, Quirk GJ (2007). Consolidation of fear extinction requires NMDA receptordependent bursting in the ventromedial prefrontal cortex. Neuron 53: 871-880.

Corcoran KA, Desmond TJ, Frey KA, Maren S (2005). Hippocampal inactivation disrupts the acquisition and contextual encoding of fear extinction. J Neurosci 25: 8978-8987.

Corcoran KA, Quirk GJ (2007). Activity in prelimbic cortex is necessary for the expression of learned, but not innate, fears. J Neurosci 27: 840-844.

Davis M (2000). The role of the amygdale in conditioned and unconditioned fear and anxiety. In: Aggleton JP (ed). The
Amygdale: A Functional Analysis. Oxford University Press: New York, pp 213-287.

Duffy S, Labrie V, Roder JC (2007). D-serine augments NMDANR2B receptor-dependent hippocampal long-term depression and spatial reversal learning. Neuropsychopharmacology 32: $1-15$.

Falls WA, Miserendino MJ, Davis M (1992). Extinction of fearpotentiated startle: blockade by infusion of an NMDA antagonist into the amygdala. J Neurosci 12: 854-863.

Fendt M, Fanselow MS (1999). The neuroanatomical and neurochemical basis of conditioned fear. Neurosci Biobehav Rev 23: 743-760.

Fox CJ, Russell K, Titterness AK, Wang YT, Christie BR (2007). Tyrosine phosphorylation of the GluR2 subunit is required for long-term depression of synaptic efficacy in young animals in vivo. Hippocampus 17: 600-605.

Fox CJ, Russell KI, Wang YT, Christie BR (2006). Contribution of NR2A and NR2B NMDA subunits to bidirectional synaptic plasticity in the hippocampus in vivo. Hippocampus 16: 907-915.

Gewirtz JC, Davis M (1997). Second-order fear conditioning prevented by blocking NMDA receptors in amygdala. Nature 388: 471-474.

Gewirtz JC, Davis M (2000). Using Pavlovian higher-order conditioning paradigms to investigate the neural substrates of emotional learning and memory. Learn Mem 7: 257-266.

Hendricson AW, Miao CL, Lippmann MJ, Morrisett RA (2002). Ifenprodil and ethanol enhance NMDA receptor-dependent long-term depression. J Pharmacol Exp Ther 301: 938-944.

Herry C, Garcia R (2002). Prefrontal cortex long-term potentiation, but not long-term depression, is associated with the maintenance of extinction of learned fear in mice. J Neurosci 22: 577-583.

Hobin JA, Goosens KA, Maren S (2003). Context-dependent neuronal activity in the lateral amygdala represents fear memories after extinction. J Neurosci 23: 8410-8416.

Izumi Y, Auberson YP, Zorumski CF (2006). Zinc modulates bidirectional hippocampal plasticity by effects on NMDA receptors. J Neurosci 26: 7181-7188.

Kentros C, Hargreaves E, Hawkins RD, Kandel ER, Shapiro M, Muller RV (1998). Abolition of long-term stability of new hippocampal place cell maps by NMDA receptor blockade. Science 280: 2121-2126.

Killcross S, Robbins TW, Everitt BJ (1997). Different types of fearconditioned behaviour mediated by separate nuclei within amygdala. Nature 388: 377-380.

Kim CH, Chung HJ, Lee HK, Huganir RL (2001). Interaction of the AMPA receptor subunit GluR2/3 with PDZ domains regulates hippocampal long-term depression. Proc Natl Acad Sci USA 98: 11725-11730.

LeDoux JE (2000). Emotion circuits in the brain. Annu Rev Neurosci 23: 155-184.

Lin CH, Lee CC, Gean PW (2003). Involvement of a calcineurin cascade in amygdala depotentiation and quenching of fear memory. Mol Pharmacol 63: 44-52.

Liu L, Wong TP, Pozza MF, Lingenhoehl K, Wang Y, Sheng M et al (2004). Role of NMDA receptor subtypes in governing the direction of hippocampal synaptic plasticity. Science 304: 1021-1024.

Luscher C, Xia H, Beattie EC, Carroll RC, von Zastrow M, Malenka RC et al (1999). Role of AMPA receptor cycling in synaptic transmission and plasticity. Neuron 24: 649-658.

Luthi A, Chittajallu R, Duprat F, Palmer MJ, Benke TA, Kidd FL et al (1999). Hippocampal LTD expression involves a pool of AMPARs regulated by the NSF-GluR2 interaction. Neuron 24: 389-399.

Malenka RC, Bear MF (2004). LTP and LTD: an embarrassment of riches. Neuron 44: 5-21. 
Man HY, Lin JW, Ju WH, Ahmadian G, Liu L, Becker LE et al (2000). Regulation of AMPA receptor-mediated synaptic transmission by clathrin-dependent receptor internalization. Neuron 25: 649-662.

Mangiavacchi S, Wolf ME (2004). Stimulation of N-methyl-Daspartate receptors, AMPA receptors or metabotropic glutamate receptors leads to rapid internalization of AMPA receptors in cultured nucleus accumbens neurons. Eur J Neurosci 20: 649-657.

Maren S (1998). Overtraining does not mitigate contextual fear conditioning deficits produced by neurotoxic lesions of the basolateral amygdala. J Neurosci 18: 3088-3097.

Maren S, Aharonov G, Stote DL, Fanselow MS (1996). N-methyl-Daspartate receptors in the basolateral amygdala are required for both acquisition and expression of conditional fear in rats. Behav Neurosci 110: 1365-1374.

Martin SJ, Grimwood PD, Morris RG (2000). Synaptic plasticity and memory: an evaluation of the hypothesis. Annu Rev Neurosci 23: 649-711.

Massey PV, Johnson BE, Moult PR, Auberson YP, Brown MW, Molnar E et al (2004). Differential roles of NR2A and NR2Bcontaining NMDA receptors in cortical long-term potentiation and long-term depression. J Neurosci 24: 7821-7828.

Morishita W, Lu W, Smith GB, Nicoll RA, Bear MF, Malenka RC (2007). Activation of NR2B-containing NMDA receptors is not required for NMDA receptor-dependent long-term depression. Neuropharmacology 52: 71-76.

Moult PR, Gladding CM, Sanderson TM, Fitzjohn SM, Bashir ZI, Molnar E et al (2006). Tyrosine phosphatases regulate AMPA receptor trafficking during metabotropic glutamate receptormediated long-term depression. J Neurosci 26: 2544-2554.

Myers KM, Ressler KJ, Davis M (2006). Different mechanisms of fear extinction dependent on length of time since fear acquisition. Learn Mem 13: 216-223.

Nakao K, Ikegaya Y, Yamada MK, Nishiyama N, Matsuki N (2002). Hippocampal long-term depression as an index of spatial working memory. Eur J Neurosci 16: 970-974.

Nijsen MJ, Croiset G, Diamant M, Stam R, Delsing D, de Wied D et al (1998). Conditioned fear-induced tachycardia in the rat: vagal involvement. Eur J Pharmacol 350: 211-222.

Noble W, Delini-Stula A (1976). Effect of oxprenolol on some fearinduced behavioral responses and hyperthermia in rats subjected to inescapable shocks. Psychopharmacology (Berl) 49: 17-22.

Pavlov IP (1927). Conditioned Reflexes. Oxford University Press: Oxford, UK.

Pellow S, Chopin P, File SE, Briley M (1985). Validation of open:closed arm entries in an elevated plus-maze as a measure of anxiety in the rat. J Neurosci Methods 14: 149-167.

Quirk GJ, Repa C, LeDoux JE (1995). Fear conditioning enhances short-latency auditory responses of lateral amygdala neurons: parallel recordings in the freely behaving rat. Neuron 15: 1029-1039.

Rescorla RA, Heth CD (1975). Reinstatement of fear to an extinguished conditioned stimulus. J Exp Psychol Anim Behav Process 1: 88-96.

Robbins SJ (1990). Mechanisms underlying spontaneous recovery in autoshaping. J Exp Psychol 16: 235-249.

Rodrigues SM, Schafe GE, LeDoux JE (2001). Intra-amygdala blockade of the NR2B subunit of the NMDA receptor disrupts the acquisition but not the expression of fear conditioning. J Neurosci 21: 6889-6896.

Rodrigues SM, Schafe GE, LeDoux JE (2004). Molecular mechanisms underlying emotional learning and memory in the lateral amygdale. Neuron 44: 75-91.
Rogan MT, Leon KS, Perez DL, Kandel ER (2005). Distinct neural signatures for safety and danger in the amygdala and striatum of the mouse. Neuron 46: 309-320.

Rumpel S, LeDoux J, Zador A, Malinow R (2005). Postsynaptic receptor trafficking underlying a form of associative learning. Science 308: 83-88.

Santini E, Ge H, Ren K, Pena de Ortiz S, Quirk GJ (2004). Consolidation of fear extinction requires protein synthesis in the medial prefrontal cortex. J Neurosci 24: 5704-5710.

Santini E, Muller RU, Quirk GJ (2001). Consolidation of extinction learning involves transfer from NMDA-independent to NMDAdependent memory. J Neurosci 21: 9009-9017.

Schwarze SR, Ho A, Vocero-Akbani A, Dowdy SF (1999). In vivo protein transduction: delivery of a biologically active protein into the mouse. Science 285: 1569-1572.

Sotres-Bayon F, Bush DE, Ledoux JE (2007). Acquisition of fear extinction requires activation of NR2B-containing NMDA receptors in the lateral amygdala. Neuropsychopharmacology 32: 1929-1940.

Tigaret CM, Thalhammer A, Rast GF, Specht CG, Auberson YP, Stewart MG et al (2006). Subunit dependencies of $N$-methylD-aspartate (NMDA) receptor-induced alpha-amino-3-hydroxy5-methyl-4-isoxazolepropionic acid (AMPA) receptor internalization. Mol Pharmacol 69: 1251-1259.

Vianna MR, Szapiro G, McGaugh JL, Medina JH, Izquierdo I (2001). Retrieval of memory for fear-motivated training initiates extinction requiring protein synthesis in the rat hippocampus. Proc Natl Acad Sci USA 98: 12251-12254.

Walker DL, Davis M (2002). The role of amygdala glutamate receptors in fear learning, fear-potentiated startle, and extinction. Pharmacol Biochem Behav 71: 379-392.

Wang YT, Linden DJ (2000). Expression of cerebellar long-term depression requires postsynaptic clathrin-mediated endocytosis. Neuron 25: 635-647.

Westbrook RF, Iordanova M, McNally G, Richardson R, Harris JA (2002). Reinstatement of fear to an extinguished conditioned stimulus: two roles for context. J Exp Psychol Anim Behav Process 28: 97-110.

Wong TP, Howland JG, Robillard JM, Ge Y, Yu W, Titterness AK et al (2007). Hippocampal long-term depression mediates acute stress-induced spatial memory retrieval impairment. Proc Natl Acad Sci USA 104: 11471-11476.

Woo NH, Teng HK, Siao CJ, Chiaruttini C, Pang PT, Milner TA et al (2005). Activation of p75NTR by proBDNF facilitates hippocampal long-term depression. Nat Neurosci 8: 1069-1077.

Xia J, Chung HJ, Wihler C, Huganir RL, Linden DJ (2000). Cerebellar long-term depression requires PKC-regulated interactions between GluR2/3 and PDZ domain-containing proteins. Neuron 28: 499-510.

Yang CH, Huang CC, Hsu KS (2005). Behavioral stress enhances hippocampal CA1 long-term depression through the blockade of the glutamate uptake. J Neurosci 25: 4288-4293.

Yang YL, Lu KT (2005). Facilitation of conditioned fear extinction by $d$-cycloserine is mediated by mitogen-activated protein kinase and phosphatidylinositol 3-kinase cascades and requires de novo protein synthesis in basolateral nucleus of amygdala. Neuroscience 134: 247-260.

Yeh SH, Mao SC, Lin HC, Gean PW (2006). Synaptic expression of glutamate receptor after encoding of fear memory in the rat amygdala. Mol Pharmacol 69: 299-308.

Young BJ, Leaton RN (1994). Fear potentiation of acoustic startle stimulus-evoked heart rate changes in rats. Behav Neurosci 108: 1065-1079. 